\title{
Formation Mechanism of Non-Metallic Inclusions in Different Stainless Steel Grades
}

\author{
Carlo MAPELLI and Paolo NOLLI ${ }^{11}$
}

Dipartimento di Meccanica-Sezione Materiali per Applicazioni Meccaniche, Politecnico di Milano, Via la Masa 34,20156 Milano, Italy. $\quad$ 1) Ph. D. Student, Dipartimento di Meccanica-Sezione Materiali per Applicazioni Meccaniche, Politecnico di Milano, Via la Masa 34, 20156 Milano, Italy.

(Received on December 6, 2002; accepted in final form on February 14, 2003)

\begin{abstract}
In this study the processing routes of three different stainless steel grades were followed; during the reducing period in the AOD plant samplings of steel and slag and measurements of temperature and oxygen activities were performed. The goal was to develop tools for the improvement in the comprehension about the development of the non metallic inclusions in stainless steels. The inclusions in the steel samples were analysed by means of a SEM and then the evaluation of the oxide activities and phases present within them was performed with Thermocalc ${ }^{\odot}$. A model developed by Janke and co-workers was implemented in order to compute the activity of elements in the liquid steel. This is based on Wagner's formalism but it is more accurate for the steel baths where solutes are not at infinite dilution. This is the reason why Janke's formalism is better than the Wagner's one in the study of stainless steels, as they are high-alloy steels. It was found that Janke's formalism lacks reliability, when it neglects some strong interactions between two elements (e.g. $\mathrm{O}$ and another element having high affinity to oxygen). The activities of oxides at the equilibrium with the liquid metal were calculated and compared to those obtained from the Thermocalc ${ }^{\odot}$-based analysis of inclusions. From this comparison some hypotheses were made about the nucleation and modification of $\mathrm{SiO}_{2}, \mathrm{Al}_{2} \mathrm{O}_{3}$ and $\mathrm{Cr}_{2} \mathrm{O}_{3}$. By making some variations to the model for the calculations of the oxides activity at the equilibrium with the steel bath, it has been also assessed how the model results are influenced by the choice of some thermodynamic parameters such as the interactions coefficients and the equilibrium constants.
\end{abstract}

KEY WORDS: stainless steels; non metallic inclusions; de-oxidation; activity; Wagner's formalism; mathematical model.

\section{Introduction}

The study of non metallic inclusions is important for two reasons. The first is their influence on the properties and the quality of steel products. This is a significant aspect from the point of view of steel product users, who have to take into account the presence of inclusions in evaluating the material behaviour in working condition. ${ }^{1)}$ The second reason is that the study of inclusions allows to estimate techniques and chemical reactions in steel refining.

The object of the present work is the characterisation and the analysis of inclusions in three different grades of stainless steel produced by a route featured by the presence of an AOD system. The goal is to achieve a better understanding of the liquid steel thermodynamic conditions during the deoxidation period for stainless steel and to set the basis for further studies, in order to develop models for the prevision of formation of the types of inclusions as a consequence of certain parameters used in the refining techniques. Moreover, another fundamental aspect would be the development of a mathematical tool to determine the refining operating steps to obtain a steel characterised by a correct inclusion population, given its desired composition and its cleanliness degree.
The study is based on the analysis of inclusions found in steel samples and the related examination of slag samples taken during the deoxidizing period. During the sampling of steel and slag from the AOD plant, also temperature and oxygen activity have been measured, to obtain a more complete description of the thermo-chemical situation. The AOD refining process was followed for three different grades: austenitic, duplex and ferritic. For the thermodynamic analysis and calculations were used two mathematical models: the first one has been developed by Janke et $a l^{2)}$ to compute the elements activity in the liquid steel and the second one, developed by Otha and Suito, ${ }^{3)}$ has been used to compute the activity of various oxides in the slag. The software Thermocalc ${ }^{\circledR}$ was used to establish the phases and the oxides activities in each analysed inclusion on the basis of its overall chemical composition and the steel bath temperature. The results based on the Thermocalc ${ }^{\complement}$ database have been used as a term of comparison to evaluate the choice of the correct thermodynamic data to improve the description of the analyzed thermodynamic system by the use of the new applied formalism.

From the metallic elements and oxygen activity, the oxide activity at the equilibrium with the liquid steel was calculated and compared to the oxide activity determined 
experimentally from the Thermocalc ${ }^{\complement}$-based analysis of inclusions.

The activity of $\mathrm{FeO}_{x}$ computed at the equilibrium with the liquid steel was compared with $\mathrm{FeO}_{x}$ activity in the slag resulting from the Otha and Suito's model.

After a comparison between theory and experimental results, changes were made to the model: Janke's model was extended from quaternary systems to larger ones; the influence of different equilibrium constants and different interaction coefficients have been assessed on the basis of the experimental results in order to choose the parameters leading to an improved correspondence between theoretical and experimental results.

\section{Mathematical Model}

The traditional method to compute the elements activity in steels is Wagner's formalism, which is based on the following expressions:

$$
\begin{array}{r}
\log \left(h_{A}\right)=\log f_{A}^{A}+\log f_{A}^{B}+\log f_{A}^{C}+\cdots+\log \% A \ldots \ldots \\
\log \left(f_{A}^{i}\right)=e_{A}^{i} \cdot \% i \ldots \ldots \ldots \ldots \ldots \ldots \ldots \ldots \ldots \ldots \ldots \ldots \ldots \ldots
\end{array}
$$

where $h_{A}$ is the henrian activity of element $A, \% i$ is the weight percentage of element $i, e_{A}^{i}$ is the interaction coefficient of element $i$ on the element $A$.

The shown expressions are proper when one considers only the first order interaction terms.

This formalism works only for dilute solutions. Thus, it does not work properly for stainless steels, as they are highalloy steels.

Janke's model is a modified formalism and it is more accurate for the study of stainless steels. It is based on the following expressions:

$$
\begin{aligned}
& \ln \left(\gamma_{l}\right)=\sum_{i=2}^{m} \varepsilon_{i}^{i}\left[x_{i}+\ln (1-x)\right] \\
& -\sum_{j=2}^{m-1} \sum_{k=j+1}^{m} \varepsilon_{j}^{k} x_{j} x_{k}\left[1+\frac{\ln \left(1-x_{j}\right)}{x_{j}}+\frac{\ln \left(1-x_{k}\right)}{x_{k}}\right] \\
& +\sum_{i=2}^{m} \sum_{\substack{k=2 \\
j \neq i}}^{m} \varepsilon_{i}^{k} x_{i} x_{k}\left[1+\frac{\ln \left(1-x_{k}\right)}{x_{k}}+\frac{1}{1-x_{i}}\right] \\
& +\frac{1}{2} \sum_{j=2}^{m-1} \sum_{k=j+1}^{m} \varepsilon_{j}^{k} x_{j}^{2} x_{k}^{2}\left[\frac{1}{1-x_{j}}+\frac{1}{1-x_{k}}-1\right] \\
& -\sum_{j=2}^{m} \sum_{\substack{k=2 \\
k \neq i)}}^{m} \varepsilon_{j}^{k} x_{j}^{2} x_{k}^{2}\left[\frac{1}{1-x_{j}}+\frac{1}{1-x_{k}}+\frac{x_{i}}{2\left(1-x_{i}\right)^{2}}-1\right] \\
& \ln \left(\gamma_{i}\right)=\ln \left(\gamma_{1}\right)+\ln \left(\gamma_{i}^{o}\right)-\varepsilon_{i}^{i} \ln \left(1-x_{i}\right) \\
& -\sum_{\substack{k=2 \\
k \neq i)}}^{m} \varepsilon_{i}^{k} x_{k}\left[1+\frac{\ln \left(1-x_{k}\right)}{x_{k}}+\frac{1}{1-x_{i}}\right] \\
& +\sum_{\substack{k=2 \\
(k \neq i)}}^{m} \varepsilon_{i}^{k} x_{k}^{2} x_{i}\left[\frac{1}{1-x_{i}}+\frac{1}{1-x_{k}}+\frac{x_{i}}{2\left(1-x_{i}\right)^{2}}-1\right]
\end{aligned}
$$

The meanings of the symbols in the expressions above are listed in Table 1.

The quaternary system approach was used in a first time. It means that the model was initially applied to various quaternary systems, $\mathrm{Fe}-\mathrm{Cr}-\mathrm{Ni}-X$, where $X$ is one of the considered elements in the thermodynamic analysis (i.e. Al, N, S, $\mathrm{Mn}, \mathrm{Si}, \mathrm{Ca}, \mathrm{O})$. This approach was used to simplify the model and because $\mathrm{Fe}, \mathrm{Cr}$ and $\mathrm{Ni}$ have the highest concentrations, so that they can be considered as reference elements.

When $X$ varies, also $\mathrm{Fe}, \mathrm{Cr}$ and $\mathrm{Ni}$ activities vary as well, but variations are small and the average values has been taken into account.

For the ferritic grade Ni is not one of the highest concentration elements, so another element could be used as the third fixed element in the quaternary systems. In spite of this situation, Ni was not replaced by another component for sake of simplicity.

Values of interaction coefficients were found in literature. ${ }^{4)}$

The relation between molar fraction-based interaction coefficients $\varepsilon_{y}^{x}$ and weight percentage-based interaction coefficients $\varepsilon_{y}^{x}$ is ${ }^{5)}$ :

$$
\varepsilon_{x}^{y}=230 \frac{M_{y}}{M_{\mathrm{Fe}}} \cdot e_{x}^{y}+\frac{M_{\mathrm{Fe}}-M_{x}}{M_{\mathrm{Fe}}}
$$

where $M_{y}, M_{x}$ and $M_{\mathrm{Fe}}$ are the molar weight of component $y$, $x$ and $\mathrm{Fe}$.

In the second stage of the thermodynamic analysis the quaternary system approach was abandoned and the complete expression of Janke's model was used with of the number of the involved elements, taking into account all elements and all interactions to compute the activity of each system component. Systems larger than quaternary were considered; they included $\mathrm{Fe}, \mathrm{Cr}, \mathrm{Ni}, \mathrm{Si}, \mathrm{Mn}, \mathrm{Al}, \mathrm{S}$ and $\mathrm{O}$.

It was observed that this approach is more accurate, as all interactions among the system elements are considered. Especially important is the effect of $\mathrm{O}$ on $\mathrm{Al}$ activity: since the interaction coefficient is negative and significant in absolute value, Al activity calculated with the complete system approach (which takes into account also the interaction of $\mathrm{O}$ ) is lower than the one calculated for the quaternary system $\mathrm{Fe}-\mathrm{Cr}-\mathrm{Ni}-\mathrm{Al}$. This shows that the quaternary system approach is not so accurate when two elements interact strongly. If this occurs, it is necessary to consider systems larger than quaternary and this action has been performed.

To compute the oxide activity in the slag, Otha and Suito's model was used. This is a simple model, validated for slag containing $\mathrm{FeO}, \mathrm{MgO}, \mathrm{CaO}, \mathrm{SiO}_{2}$ and $\mathrm{Al}_{2} \mathrm{O}_{3}$ at $1873 \mathrm{~K}$, and the activity computations has been performed

Table 1. Meaning of the symbols appearing in Eqs. (3) and (4).

\begin{tabular}{|c|c|}
\hline Symbol & Meaning \\
\hline $\mathrm{x}_{\mathrm{i}}$ & molar fraction of component $i$ \\
\hline$\varepsilon_{i}^{i}$ & $\begin{array}{c}\text { interaction coefficient of solute } i \\
\text { based on molar fraction }\end{array}$ \\
\hline$\gamma_{i}^{o}$ & raoultian activity coefficient of solute $i$ at infinite dilution \\
\hline$\gamma_{i}$ & raoultian activity coefficient of solute $i$ \\
\hline$\gamma_{i}$ & solvent raoultian activity coefficient \\
\hline
\end{tabular}


by the empirical relations stated in this method, although in this study the temperatures has not been maintained constant and other oxides contained in the slag have been present (such as $\mathrm{Cr}_{2} \mathrm{O}_{3}$ ), even if in small concentrations:

$$
\begin{aligned}
& \log \gamma_{\mathrm{FeO}}=\frac{0.676 \cdot \% \mathrm{MgO}+0.267 \cdot \% \mathrm{Al}_{2} \mathrm{O}_{3}-19.07}{\% \mathrm{SiO}_{2}} \\
& +0.0214 \cdot \% \mathrm{CaO}-0.047 \\
& \log \gamma_{\mathrm{MnO}}=+0.019 \cdot \% \mathrm{CaO}+0.023 \cdot \% \mathrm{MgO} \\
& -0.023 \cdot \% \mathrm{SiO}_{2}+0.129 \\
& \log \gamma_{\mathrm{SiO}_{2}}=0.036 \cdot \% \mathrm{MgO}+0.061 \cdot \% \mathrm{Al}_{2} \mathrm{O}_{3}+0.123 \cdot \% \mathrm{SiO}_{2} \\
& -0.595 \frac{\% \mathrm{SiO}_{2}}{\% \mathrm{CaO}}-6.456 \\
& \log \gamma_{\mathrm{Al}_{2} \mathrm{O}_{3}}=\frac{-0.025 \cdot \% \mathrm{CaO}+0.167 \cdot \% \mathrm{MgO}}{\% \mathrm{SiO}_{2}} \\
& +0.033 \cdot \% \mathrm{Al}_{2} \mathrm{O}-1.56
\end{aligned}
$$

When comparing the results of this model to the results obtained with Thermocalc $^{\odot}$ at the effective temperatures, the observed differences have not been very large (within the same order of magnitude). Thus, this model was used also for temperatures different from $1873 \mathrm{~K}$, and this confirm the correctness of the assumed hypothesis for the use of this briefly described method.

\section{Experimental Procedure}

Three stainless steel grades were studied: six processing routes of austenitic, four routes of duplex and four routes of ferritic.

The attention was focused on the reducing steps of the refining process. Samplings were made according to the following procedure:

- 2 or 3 samplings in the AOD converter after the addition of the deoxidizing mix

- 1 in the AOD converter during desulphurization (if required in the process)

- 1 in the ladle

- 1 in the tundish after $30 \mathrm{~min}$ or $45 \mathrm{~min}$.

In each sampling were taken a sample of slag and a sample of liquid steel and the temperature and oxygen activity measurements were performed.

Below a brief description of the process for each steel grade is given.

The austenitic stainless steel has been treated on the basis of particular procedure parameters (Table 2). This grade is similar to AISI 304; it is not low carbon and it is sulphurized. The EAF charge is made of $\mathrm{Fe}-\mathrm{Cr}-\mathrm{C}(65 \%$ $\mathrm{Cr}, 7 \% \mathrm{C}$ ), $18 \% \mathrm{Cr}-8 \% \mathrm{Ni}$ scrap, lime and coke (for foaming slag and its reduction). The EAF process was not fol-

Table 2. Chemical analysis of the studied austenitic, duplex and ferritic stainless steels.

\begin{tabular}{|c|c|c|c|c|c|c|c|c|c|c|c|}
\hline Grade & $\boldsymbol{C}$ & $\boldsymbol{S i}$ & $\boldsymbol{M n}$ & \multicolumn{1}{c}{$\boldsymbol{C}$} & $\boldsymbol{N} \boldsymbol{i}$ & $\boldsymbol{M o}$ & \multicolumn{1}{|c|}{$\boldsymbol{S}$} & $\boldsymbol{P}$ & $\boldsymbol{N}$ & $\boldsymbol{C u}$ & $\boldsymbol{C o}$ \\
\hline \multirow{2}{*}{ Austenitic } & 0,05 & 0,20 & 0,50 & 18,00 & 8,50 & & 0,020 & 0,040 & 0,10 & & \\
& $\max$ & 1,00 & 2,00 & $\mathrm{z} 19,00$ & 10,00 & - & 0,070 & $\max$ & $\max$ & - & - \\
\hline \multirow{2}{*}{ Duplex } & 0,02 & 0,40 & 1,40 & 22,50 & 5,00 & 3,15 & 0,005 & 0,030 & 0,160 & 0,50 & 0,30 \\
& $\max$ & 0,60 & 1,60 & 22,90 & 5,40 & 3,40 & $\max$ & $\max$ & 0,180 & $\max$ & $\max$ \\
\hline \multirow{2}{*}{ Ferritic } & 0,025 & 0,30 & 0,35 & 16,50 & 0,25 & 0,10 & 0,003 & 0,030 & 0,02 & 0,20 & - \\
& $\max$ & 0,50 & 0,55 & 17,00 & $\max$ & $\max$ & $\max$ & $\max$ & $\max$ & $\max$ & - \\
\hline
\end{tabular}

lowed in details. Its processing route is as follows:

- Melting in EAF

- AOD Refining

- Oxidising Period

1 Step- $\mathrm{O}_{2}: \mathrm{N}_{2}=3: 1$ Addition of $\mathrm{CaO}$, metallic charge ( $\mathrm{Fe}-\mathrm{Cr}-\mathrm{C}$; scrap)

2 Step- $\mathrm{O}_{2}: \mathrm{N}_{2}=1: 1$ Addition of $\mathrm{CaO}$, metallic charge (Ni; scrap)

3 Step- $\mathrm{O}_{2}: \mathrm{N} 2=1: 2$

Addition of $\mathrm{CaO}$, metallic charge ( $\mathrm{Ni}$; scrap)

- Reduction Period

Addition of $\mathrm{CaO}, \mathrm{CaF}_{2}$ and of the deoxidizing mix:

$\mathrm{FeSi}(75 \% \mathrm{Si}) ; \mathrm{SiMn}(33 \% \mathrm{Si}, 66 \% \mathrm{Mn})$

Scorification

Addition of metallic charge (for composition cor-

- Ladle rection or as coolant)

Addition of pyrite while tapping into the ladle

Stirring with Ar for about 20,

Addition of pyrite wires

- Continuous Casting

The studied duplex stainless steel (Table 2) is a low carbon and desulphurized grade; moreover it is subjected to $\mathrm{CaSi}$ treatment for inclusions modification. The EAF charge is the same as that mentioned for the austenitic grade. Its processing route is described below:

- Melting in EAF

- AOD Refining

- Oxidizing Period

1 Step- $\mathrm{O}_{2}: \mathrm{N}_{2}=3: 1$

Addition of $\mathrm{CaO}$, metallic charge ( $\mathrm{Fe}-\mathrm{Cr}-\mathrm{C}$; scrap)

2 Step- $\mathrm{O}_{2}: \mathrm{N}_{2}=1: 1$

Addition of $\mathrm{CaO}$ and $\mathrm{MoO}_{x}$, metallic charge (scrap)

3 Step- $\mathrm{O}_{2}: \mathrm{N}_{2}=1: 2$

Addition of $\mathrm{CaO}$ and $\mathrm{MoO}_{x}$, metallic charge (scrap)

4 Step- $\mathrm{O}_{2}: \mathrm{Ar}=1: 3$

Addition of $\mathrm{CaO}$ and $\mathrm{MoO}_{x}$, metallic charge $(\mathrm{Ni}$; scrap)

- Reduction Period

Addition of $\mathrm{CaO}, \mathrm{CaF}_{2}$, bauxite and of the deoxidizing mix: $\mathrm{FeSi}(75 \% \mathrm{Si})$; $\mathrm{SiMn}(33 \% \mathrm{Si}, 66 \% \mathrm{Mn})$ and aluminium

Scorification

Addition of metallic charge (for composition correction or as coolant)

- Desulphurization

- Ladle

$$
\text { Addition of } \mathrm{CaO}, \mathrm{CaF}_{2} \text { and } \mathrm{FeSi}(75 \% \mathrm{Si})
$$

$\mathrm{N}_{2}$ insufflation to get the right composition

Addition of $\mathrm{CaSi}$ wires for inclusion modification

- Ingot castings

The ferritic grade corresponds to AISI 430L (Table 2).

Its process is briefly described below:

- Melting in EAF

- AOD Refining

- Oxidizing Period

1 Step $-\mathrm{O}_{2}: \mathrm{N}_{2}=4.5: 1$ for $2 / 3$ of the period; $\mathrm{O}_{2}: \mathrm{Ar}=$ $4.5: 1$ per $1 / 3$ of the period

Addition of $\mathrm{CaO}$, metallic charge ( $\mathrm{Fe}-\mathrm{Cr}-\mathrm{C}$; scrap)

2 Step- $\mathrm{O}_{2}: \mathrm{Ar}=26: 15$

Addition of $\mathrm{CaO}$, metallic charge (scrap) 
3 Step- $\mathrm{O}_{2}: \mathrm{Ar}=13: 25$

Addition of $\mathrm{CaO}$, metallic charge (scrap)

4 Step- $\mathrm{O}_{2}: \mathrm{Ar}=10: 24$

Addition of $\mathrm{CaO}$, metallic charge (scrap)

- Reduction Period

Addition of $\mathrm{CaO}, \mathrm{CaF}_{2}$ and $\mathrm{FeSi}(75 \% \mathrm{Si})$

Scorification

Addition of metallic charge (for composition correction or as coolant)

- Desulphurization

Addition of $\mathrm{CaO}, \mathrm{CaF}_{2}$ and $\mathrm{Al}$

- Ladle Furnace

Electromagnetic stirring

- Continuous Casting

Slag samples were analysed quantitatively by means of the SEM with EDS technique at Dipartimento di Meccanica of Politecnico di Milano.

To determine the composition of the slag six measurements were made for each sample by EDS, using a SEM magnification of about $150-350 \times$, in order to get the mean composition at a scale at which the slag can be thought homogeneous. Then the average of the six results was considered. The elements detected by the SEM have been: $\mathrm{Ca}, \mathrm{Fe}$, $\mathrm{Si}, \mathrm{S}, \mathrm{Al}, \mathrm{Mg}, \mathrm{K}, \mathrm{P}, \mathrm{Mn}, \mathrm{Cr}$, and $\mathrm{Ni}$.

SEM with EDS technique cannot reveal quantitatively the lightest elements like $\mathrm{O}$ and $\mathrm{F}$. Thus, the presence of $\mathrm{CaF}_{2}$ was neglected and all the $\mathrm{Ca}$ has been regarded as forming $\mathrm{CaO}$ or $\mathrm{CaS}$.

To calculate the slag composition the following compounds were considered: $\mathrm{CaO}, \mathrm{CaS}, \mathrm{FeO}, \mathrm{SiO}_{2}, \mathrm{MgO}$, $\mathrm{MnO}, \mathrm{Al}_{2} \mathrm{O}_{3}, \mathrm{Cr}_{2} \mathrm{O}_{3}, \mathrm{~K}_{2} \mathrm{O}$ and $\mathrm{P}_{2} \mathrm{O}_{5}$.

SEM measures the atomic percentages of the detected atoms, thus the following expressions were used to compute the mole fraction composition:

$$
\begin{aligned}
& X_{\mathrm{CaS}}= \frac{\% \mathrm{~S}}{\sum_{j \neq \mathrm{Ca}} \frac{\% M j}{x j}+\% \mathrm{Ca}} . \\
& X_{\mathrm{CaO}}=\frac{\% \mathrm{Ca}-\% \mathrm{~S}}{\sum_{j \neq \mathrm{Ca}} \frac{\% M j}{x j}+\% \mathrm{Ca}} . \\
& X_{M_{i_{i i}} \mathrm{O}_{y i}}=\frac{\frac{\% M i}{x i}}{\sum_{j \neq \mathrm{Ca}} \frac{\% M j}{x j}+\% \mathrm{Ca}}
\end{aligned}
$$

$\% M i$ is the atomic percentage measured by SEM and $M i_{x i} \mathrm{O}_{y i}$ is a generic oxide.

The steel samples composition was measured by means of a spectrometer; then after polishing, the contained inclusions were quantitatively analysed in the same way as the slag samples. Analyses were made at high magnification ( $3000 \mathrm{X}$ ) because of the very small size of the most of inclusions (order of microns).

Often a problem in this quantitative analysis is that SEM detects not only atoms in the inclusion but also in the metal matrix, because the scanned area is larger than the inclusion itself. Thus a way to "filter" the SEM results must be found.
It was thought that all the detected Fe atoms were in the matrix and not in the inclusions; thus if $\% \mathrm{Fe}$ is the atomic percentage of iron atoms measured by SEM and if $x_{\mathrm{Fe}}$ and $x_{M i}$ are the mole fractions of $\mathrm{Fe}$ and of the element $M i$ in the liquid steel, respectively, then the quantity

$$
\frac{X_{M i}}{X_{\mathrm{Fe}}} \% \% \mathrm{Fe}
$$

is the percentage amount of $M i$ atoms detected by SEM that is in the metal matrix and not in the inclusion. So the expression above has to be subtracted from each \%Mi given by EDS measurements.

From the corrected \%Mi, inclusion compositions can be determined in the same way as for slag samples. The following compounds were considered: $\mathrm{CaO}, \mathrm{SiO}_{2}, \mathrm{MnO}$, $\mathrm{MnS}, \mathrm{Al}_{2} \mathrm{O}_{3}, \mathrm{MgO}, \mathrm{TiO}_{2}$ and $\mathrm{Cr}_{2} \mathrm{O}_{3}$. From the composition of the inclusions the assessment of the activities and of the phases contained in the oxides and in the sulphides has been made by Thermocalc ${ }^{\circ}$.

At this stage of the thermodynamic analysis the available data are:

- temperature,

- free oxygen activity,

- liquid steel composition,

- slag composition,

- inclusions composition with phases and activities of present compounds.

Then Janke's model was used to calculate the activities of elements in the liquid steel. From elements and oxygen activities in the liquid metal, the activities of oxides at the equilibrium with the steel bath were determined. The expression used for the equilibrium constants was:

$$
K_{\mathrm{eq}}=\frac{a_{M_{x} \mathrm{O}_{y}}}{a_{M}^{x} \cdot h_{\mathrm{O}}^{y}}
$$

Constants were computed both

- combining the expressions:

$$
K^{\prime}=\frac{h_{M}^{x} \cdot h_{\mathrm{O}}^{y}}{a_{M_{x} \mathrm{O}_{y}}}
$$

and

$$
a_{M}=\frac{h_{M} \cdot \gamma_{M}^{\circ} \cdot M_{\mathrm{Fe}}}{100 M_{M}}
$$

or

$$
a_{M}=\frac{h_{M} \cdot \gamma_{M}^{\circ} \cdot M_{\mathrm{Fe}}}{M_{\mathrm{Fe}}+99 M_{M}}
$$

from the thermodynamic data found in literature (Table 3). - and combining the expressions

$$
K^{\prime \prime}=\exp \left(-\frac{\Delta G^{\circ}}{R \cdot T}\right)=\frac{a_{M_{x} \mathrm{O}_{y}}}{p_{\mathrm{O}_{2}}^{y / 2} \cdot a_{M}^{x}}
$$

and

$$
\log \left(K^{\prime \prime \prime}\right)=\log \left(\frac{h_{\mathrm{O}}}{p_{\mathrm{O}_{2}}^{1 / 2}}\right)=\frac{5832}{T}+0.356
$$


Table 3. Equilibrium constants for the formation of the studied oxide compound. ${ }^{6}$

\begin{tabular}{|l|c|l|}
\hline Oxide & \multicolumn{1}{|c|}{$\mathbf{L o g} \boldsymbol{K}^{\prime}$} & $\boldsymbol{K}^{\prime}$ at $1873 \mathrm{~K}$ \\
\hline $\mathrm{Al}_{2} \mathrm{O}_{3}$ & $-\frac{64000}{T}+20,57$ & $2,5 \cdot 10^{-14}$ \\
\hline $\mathrm{CaO}$ & & $9,0 \cdot 10^{-7}$ \\
\hline $\mathrm{Cr}_{2} \mathrm{O}_{3}$ & $-\frac{49740}{T}+17,78$ & $1,1 \cdot 10^{-4}$ \\
\hline $\mathrm{MnO}$ & $-\frac{15720}{T}+7,18$ & $6,1 \cdot 10^{-2}$ \\
\hline $\mathrm{SiO}_{2}$ & $-\frac{30410}{T}+11,59$ & $2,3 \cdot 10^{-5}$ \\
\hline
\end{tabular}

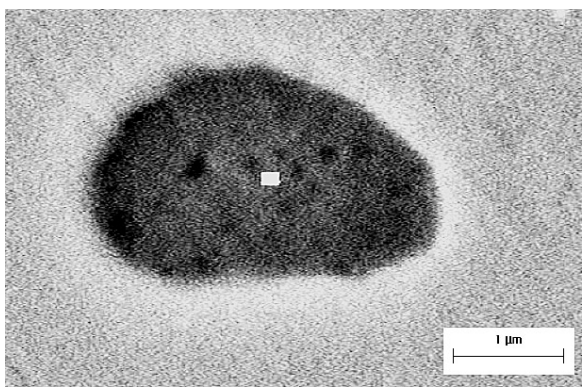

Fig. 1. SEM image of an inclusion containing $\mathrm{Mn}, \mathrm{S}$ and $\mathrm{Cr}$.

Table 4. Average chemical composition of sulphide inclusions observed in the austenitic grade.

\begin{tabular}{|l|l|l|l|}
\cline { 2 - 4 } \multicolumn{1}{c|}{} & $\boldsymbol{S}$ & $\mathbf{M n}$ & $\mathrm{Cr}$ \\
\hline Atomic percentage & $\sim 40 \%$ & $\sim 45 \%$ & $\sim 7 \%$ \\
\hline
\end{tabular}

where $\Delta G^{\circ}$ is calculated from data in literature. ${ }^{7)}$

The calculated oxide activities were compared to the activities obtained with Thermocalc ${ }^{\mathscr{O}}$ analysis of inclusions.

Otha and Suito's model was used to compute the activities of oxides (especially $\mathrm{FeO}_{x}$ ) in the slag.

The activity of $\mathrm{FeO}_{x}$ at the equilibrium with the liquid steel was compared to its activity in the slag computed by the Otha and Suito's model.

\section{Results}

\subsection{Austenitic Steel}

As mentioned above, the austenitic grade is sulphurized; thus sulphur-containing inclusions are the most numerous. Such inclusions contain mainly $\mathrm{Mn}, \mathrm{S}$ and $\mathrm{Cr}$ (Fig. 1). The typical composition is in Table 4. According to Thermocalc $^{\mathcal{O}}$ calculations, the $\mathrm{Cr}$ is contained as $\mathrm{Cr}_{2} \mathrm{O}_{3}$, while the others as pure $\mathrm{MnS}$ and liquid.

The deoxidation is made by adding FeSi and SiMn. As a consequence of the addition other two types of inclusions can be found. The first is formed by $\mathrm{Si}$ and $\mathrm{Cr}$ oxides (Table 5, Fig. 2) and is present in the samples taken after the addition and at the end of the process.

They are made of pure $\mathrm{SiO}_{2}$ and pure $\mathrm{Cr}_{2} \mathrm{O}_{3}$. The second type of inclusion contains $\mathrm{Si}, \mathrm{S}, \mathrm{Al}, \mathrm{Mg}, \mathrm{Mn}$, and $\mathrm{Cr}$ in the percentage amounts in Table 6. Such inclusions are present in the samples taken from the ladle and from the tundish (with a higher content of sulphur in the latter).

Thermocalc ${ }^{\mathcal{O}}$ analysis establishes these inclusions are made of a liquid phase, pure $\mathrm{MnS}$ and pure $\mathrm{Cr}_{2} \mathrm{O}_{3}$. Also silico-aluminates (Table 7, Fig. 4) can be found but not in all the observed samples.
Table 5. Average amount of chemical elements present in a type of inclusion observed after the addition of FeSi.

\begin{tabular}{|l|l|l|}
\cline { 2 - 3 } \multicolumn{1}{c|}{} & $\mathrm{Si}$ & $\mathrm{Cr}$ \\
\hline Atomic percentage & $\sim 97 \%$ & $\sim 3 \%$ \\
\hline
\end{tabular}

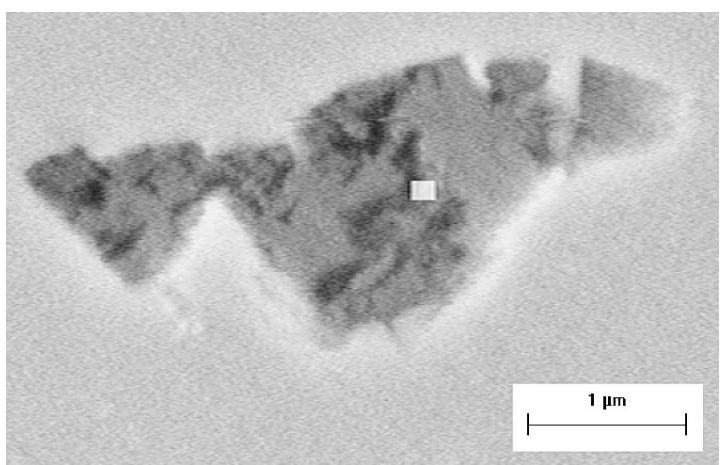

Fig. 2. SEM image of an inclusion containing $\mathrm{Si}$ and $\mathrm{Cr}$.

Table 6. Average content of $\mathrm{Si}, \mathrm{S}, \mathrm{Al}, \mathrm{Mg}, \mathrm{Mn}$ and $\mathrm{Cr}$ contained in the second type of inclusion observed after the addition of FeSi and SiMn.

\begin{tabular}{|c|c|c|c|c|c|c|}
\hline & Si & $S$ & $A l$ & $M g$ & Mn & $\mathrm{Cr}$ \\
\hline Atomic percentage & $\begin{array}{l}35 \% \\
40 \% \\
\end{array}$ & $\sim 3 \%$ & $\begin{array}{l}10 \% \\
15 \% \\
\end{array}$ & $-5 \%$ & $\begin{array}{l}25 \% \\
30 \% \\
\end{array}$ & $\sim 7 \%$ \\
\hline
\end{tabular}

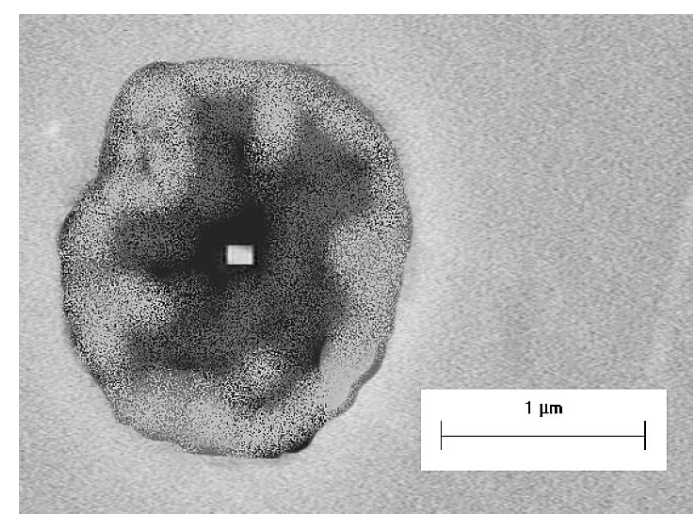

Fig. 3. SEM image of an inclusion containing $\mathrm{Si}, \mathrm{S}, \mathrm{Al}, \mathrm{Mg}, \mathrm{Mn}$ and $\mathrm{Cr}$

Table 7. Composition of silico-aluminates in the austenitic stainless steel.

\begin{tabular}{|l|l|l|l|l|}
\cline { 2 - 5 } \multicolumn{1}{c|}{} & $\boldsymbol{C a}$ & $\boldsymbol{S i}$ & $\boldsymbol{A l}$ & $\boldsymbol{M g}$ \\
\hline \multirow{2}{*}{ Atomic percentage } & $25 \%$ & $30 \%$ & & \multirow{2}{*}{$10 \%$} \\
& $35 \%$ & $35 \%$ & & $20 \%$ \\
\hline
\end{tabular}

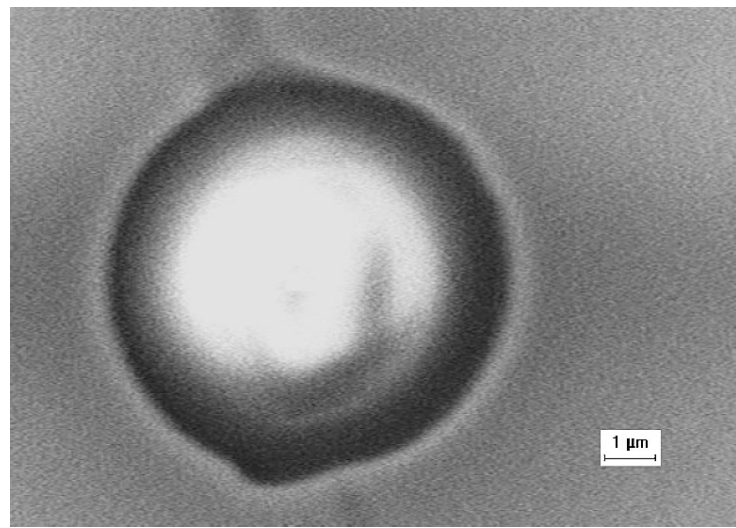

Fig. 4. SEM image of an observed silico-aluminate. 


\subsection{Duplex Stainless Steel}

This grade is deoxidized with FeSi, SiMn and Al. Thus, the inclusions containing $\mathrm{Si}$ and $\mathrm{Cr}$ and the inclusions containing $\mathrm{Si}, \mathrm{S}, \mathrm{Al}, \mathrm{Mg}, \mathrm{Mn}$ and $\mathrm{Cr}$, both of which are discussed in the previous paragraph, are present in this steel grade as well.

After desulphurization another type of inclusions is dominant (Table 8, Fig. 5). According to Thermocalc ${ }^{\circledR}$ calcula-

Table 8. Average amount of chemical elements contained in some usual inclusions in the studied duplex stainless steel.

\begin{tabular}{|l|l|l|l|l|}
\cline { 2 - 5 } \multicolumn{1}{c|}{} & $\boldsymbol{A l}$ & $\mathbf{M g}$ & $\mathbf{M n}$ & $\mathrm{Cr}$ \\
\hline Atomic percentage & $\sim 70 \%$ & $\sim 15 \%$ & $5-7 \%$ & $\sim 5 \%$ \\
\hline
\end{tabular}

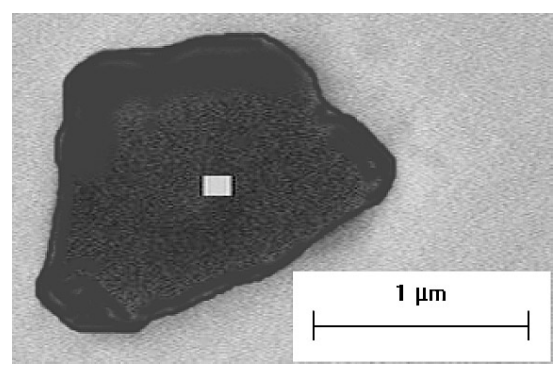

Fig. 5. SEM image of an inclusion observed in the duplex stainless steel after desulphurization.

Table 9. Average amount of chemical elements contained in some inclusions after CaSi treatment.

\begin{tabular}{|l|l|l|l|l|l|}
\cline { 2 - 6 } \multicolumn{1}{c|}{} & $\boldsymbol{A l}$ & $\mathbf{M g}$ & $\boldsymbol{C a}$ & $\mathrm{Si}$ & $\boldsymbol{C r}$ \\
\hline Atomic percentage & $\sim 50 \%$ & $\sim 20 \%$ & $10-15 \%$ & $\sim 7 \%$ & $\sim 5 \%$ \\
\hline
\end{tabular}

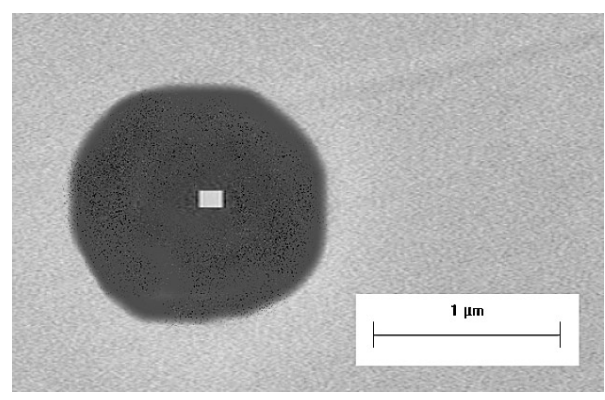

Fig. 6. SEM image of an inclusion observed in the duplex stainless steel after calcium treatment realized by $\mathrm{CaSi}$ addition. tions it is made of a liquid phase, pure $\mathrm{Al}_{2} \mathrm{O}_{3}$ and spinel $\mathrm{MgO} \cdot \mathrm{Al}_{2} \mathrm{O}_{3}$. After $\mathrm{CaSi}$ treatment for inclusion modification, another type of inclusion has been found (Table 9, Fig. 6): Thermocalc ${ }^{\odot}$ analysis establishes that these inclusions are formed of a liquid phase, $\mathrm{MgO} \cdot \mathrm{Al}_{2} \mathrm{O}_{3}$ and pure $\mathrm{Cr}_{2} \mathrm{O}_{3}$.

\subsection{Ferritic Stainless Steel}

This grade is deoxidized with FeSi and Al is added during the desulphurization period. The dominant type of inclusions is that containing $\mathrm{Si}(97 \%)$ and $\mathrm{Cr}(3 \%)$. Similar to these inclusions are those containing $\mathrm{Al}$ and $\mathrm{Cr}$, which can be found in samples taken after desulphurization (Fig. 7). In the samples taken from the tundish inclusions that contain $\mathrm{Al}, \mathrm{Mg}$ and $\mathrm{Cr}$ in a large range of composition (Table 10) and are polluted by $\mathrm{Zr}$ are found (Fig. 8). Neglecting the presence of $\mathrm{Zr}$, Thermocalc ${ }^{\odot}$ calculates that these inclusions contain pure $\mathrm{Al}_{2} \mathrm{O}_{3}$, pure $\mathrm{Cr}_{2} \mathrm{O}_{3}$ and $\mathrm{MgO} \cdot \mathrm{Al}_{2} \mathrm{O}_{3}$.

\section{Discussion}

To compute the oxide activity at the equilibrium with the steel bath, a model was first realized.

From the steel molar fraction composition and the interaction coefficients it is possible to calculate the elements activities in the liquid according to the quaternary systems approach.

From the elements activities so computed, the oxygen activity measured by oxygen probe (CELOX), the $\mathrm{FeO}_{x}$ activity previously computed with the Otha and Suito's model, the temperature and the expressions for the equilibrium constants, it is possible to calculate the oxide activities at the equilibrium with the liquid steel and the oxygen activity in the metal bath obtained with the assumption that $\mathrm{FeO}_{x}$ in the slag and Fe in the steel are at the equilibrium.

Then the computed activities of oxides can be compared to their activities determined by Thermocalc $^{\odot}$ analysis of inclusions.

When comparing the oxygen activity computed in the

Table 10. Average amount of chemical elements observed in a type of inclusion present in the studied ferritic steel.

\begin{tabular}{|l|l|l|l|}
\cline { 2 - 4 } \multicolumn{1}{c|}{} & $\boldsymbol{A l}$ & $\mathbf{M g}$ & $\mathrm{Cr}$ \\
\hline Atomic percentage & $\sim 40 \%$ & $\sim 50 \%$ & $\sim 5 \%$ \\
\hline
\end{tabular}

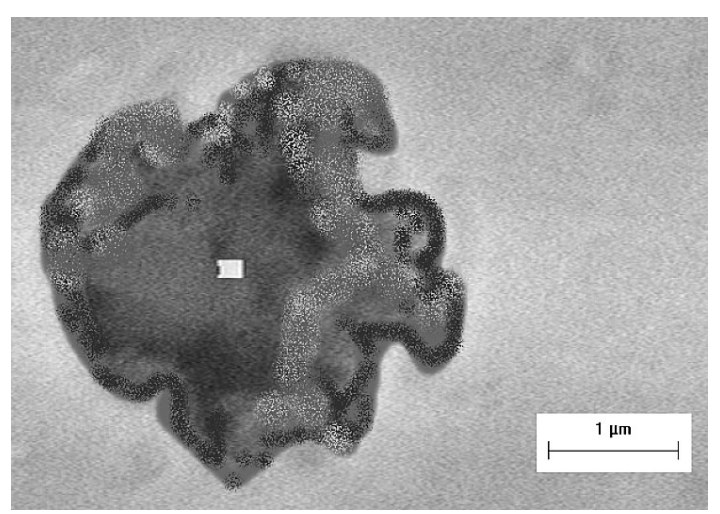

Fig. 8. SEM image of an inclusion in a sample taken from the tundish.
Fig. 7. (A): inclusion containing $\mathrm{Si}$ and $\mathrm{Cr}$. (B): inclusion containing $\mathrm{Al}$ and $\mathrm{Cr}$.

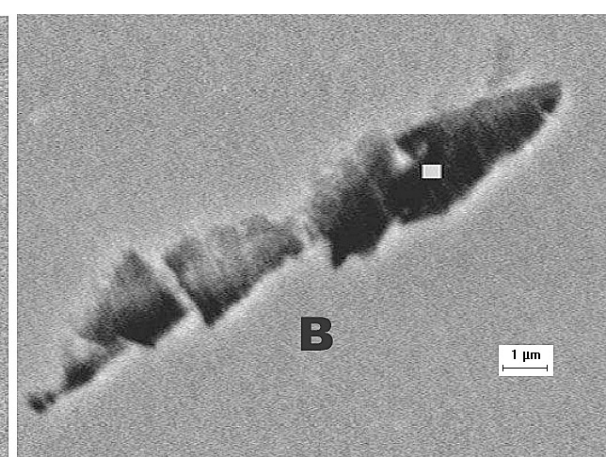


equilibrium condition between $\mathrm{FeO}_{x}$ in the slag and $\mathrm{Fe}$ in the liquid steel to the measurement, it is noticed that the two values are close for those samples taken just after the addition of the deoxidizing mix of chemical elements, showing an average difference of $1.7 \cdot 10^{-4}$. For the later stages of the refining process the calculated value and the measured value in the metal bath differ significantly, because the first one is higher than the second one.

Thus the slag that forms after the addition of the deoxidizing mix (during the oxidising period slag does not form) is nearly at the equilibrium with the steel bath, but later the thermodynamic condition of the slag gets far from the condition of equilibrium with the liquid metal showing an average difference of $1.1 \cdot 10^{-3}$ at the end of the refining process. This can be due to the kinetics of the composition variation within the slag, which is the consequence of additions and scorifications, and to the effect of $\mathrm{CaF}_{2}$, which is to be evaluated more precisely.

Some considerations have to be done about $\mathrm{Cr}_{2} \mathrm{O}_{3}$. For most of the analysed inclusions Thermocalc $^{\odot}$ established the presence of pure $\mathrm{Cr}_{2} \mathrm{O}_{3}$; thus the experimental analysis led to assign to this oxide an activity value equal to 1 , but the model calculated that the activity of this oxide at the equilibrium with the liquid steel was lower than 1 (chromium, which is oxidised during the decarburization, is effectively recovered). This difference is probably due to the fact that $\mathrm{Cr}_{2} \mathrm{O}_{3}$ forms during the oxidizing period and acts as nucleant for inclusions that form during the de-oxidation, so that it can not be reduced, being trapped in the inclusions.

Further considerations concern $\mathrm{SiO}_{2}$ and $\mathrm{Al}_{2} \mathrm{O}_{3}$. For this last oxide the mathematical model computed activity values much larger than 1, thus asserting the possible formation of pure alumina. However, during the experimental analysis of inclusions pure alumina was found only in some samples taken in certain moments (after desulphurization, in the ladle and in the tundish) of the duplex and of the ferritic grades process. The disagreement between experimental results and model equilibrium predictions may lead to think that $\mathrm{Al}_{2} \mathrm{O}_{3}$ has very slow kinetics, which is likely due to its high surface tension, but this cannot be certainly proved. So, some corrections are applied to the model and are explained later in the script. These modifications produce a better agreement between the value of $\mathrm{Al}_{2} \mathrm{O}_{3}$ activity calculated and that obtained with the experimental analysis.

Concerning $\mathrm{SiO}_{2}$, the opposite problem was encountered: in a lot of samples pure silica was found, while the model excluded its presence, assigning its activity a value lower than 1 .

The austenitic and the duplex grades are deoxidized respectively with FeSi and $\mathrm{SiMn}$, and with $\mathrm{FeSi}, \mathrm{SiMn}$ and Al. For these grades pure $\mathrm{SiO}_{2}$ can be found in the samples taken just after the addition of the deoxidizing mix and in the samples taken from the tundish.

For the ferritic grade, which is deoxidized only with FeSi and $\mathrm{Al}$, the latter being added only for desulphurization, pure $\mathrm{SiO}_{2}$ can be found almost in every process moment.

It can be inferred that pure $\mathrm{SiO}_{2}$ forms when $\mathrm{FeSi}$ is added and the oxygen activity is still high. Later, when the oxygen potential gets lower, the pure silica is not stable any more.
For the duplex and the austenitic grades the modification of pure $\mathrm{SiO}_{2}$ inclusions could be favoured by their combination with the inclusions containing $\mathrm{Si}, \mathrm{S}, \mathrm{Al}, \mathrm{Mg}, \mathrm{Mn}$ and $\mathrm{Cr}$, which can form after the addition of SiMn. It is also likely that pure silica inclusions are modified and reduced by $\mathrm{Al}$ (for the duplex grade).

On the other hand, for the ferritic grade, the modification of pure $\mathrm{SiO}_{2}$ inclusions is not favoured by the presence of inclusions of the Mn-containing type. Moreover, when $\mathrm{Al}$ is added during the desulphurization, it forms pure $\mathrm{Al}_{2} \mathrm{O}_{3}$ but can also reduce $\mathrm{SiO}_{2}$.

It is possible to notice that, the higher is the Mn content, which is low for the ferritic grade and higher for the austenitic and duplex, the more Mn can facilitate the modification of $\mathrm{SiO}_{2}$ inclusions.

In a later stage of the mathematical model development and of the comparison between data and predictions, corrections were made to the model itself, in order not only to get a better agreement with the experimental results, but also to assess how the model predictions can be influenced by the choice of the equilibrium constants and of the interaction coefficients found in literature, and how the model results change when the complete expression of Janke's formalism is used instead of the quaternary systems approach. Thus, Janke's formalism was applied to systems composed of $\mathrm{Fe}, \mathrm{Cr}, \mathrm{Ni}, \mathrm{Si}, \mathrm{Mn}, \mathrm{Al}, \mathrm{S}$ and $\mathrm{O}$ and no more to quaternary systems.

Equilibrium constants, different from those used in the earlier stage of the analysis, were used especially for $\mathrm{Cr}_{2} \mathrm{O}_{3}$, $\mathrm{SiO}_{2}$ and $\mathrm{Al}_{2} \mathrm{O}_{3}$ (Table 11).

Concerning the effect of oxygen on the calculated $\mathrm{Al}$ activity, it has to be said that the interaction coefficient $\varepsilon_{\mathrm{O}}^{\mathrm{Al}}$ is negative and high in absolute value $\left(-433^{5)}\right)$ so that the newly computed $\mathrm{Al}$ activity is lower than that calculated for the quaternary system $\mathrm{Fe}-\mathrm{Cr}-\mathrm{Ni}-\mathrm{Al}$.

Despite the corrections for alumina, the computed values of activity were still higher than those obtained from the analysis of inclusions based on Thermocalc ${ }^{\circ}$, although they are usually lower than one.

By using $64^{4)}$ as the value for the interaction coefficient $\varepsilon_{\mathrm{Si}}^{\mathrm{Mn}}$, the $\mathrm{SiO}_{2}$ activity values computed by the model were closer to those obtained by Thermocalc ${ }^{\mathcal{O}}$ inclusion analysis, but they were still lower than those evaluated from the ex-

Table 11. Used equilibrium constants in the modified formalism.

\begin{tabular}{|l|c|}
\hline Oxide & logKeq \\
\hline $\mathrm{Al}_{2} \mathrm{O}_{3}$ & $-\frac{58600}{T}+18,90^{6)}$ \\
\hline $\mathrm{Al}_{2} \mathrm{O}_{3}$ & $-\frac{62780}{T}+20,5^{6)}$ \\
\hline $\mathrm{Al}_{2} \mathrm{O}_{3}$ & $-\frac{64000}{T}+20,57^{6)}$ \\
\hline $\mathrm{Cr}_{2} \mathrm{O}_{3}$ & $-\frac{40740}{T}+17,78^{6)}$ \\
\hline $\mathrm{Cr}_{2} \mathrm{O}_{3}$ & $-\frac{438560}{T}+19,55^{2)}$ \\
\hline $\mathrm{SiO}_{2}$ & $-\frac{29850}{T}+11,20^{6)}$ \\
\hline $\mathrm{SiO}_{2}$ & $-\frac{30410}{T}+11,59^{6)}$ \\
\hline $\mathrm{SiO}_{2}$ & $-\frac{30100}{T}+11,40^{2)}$ \\
\hline
\end{tabular}




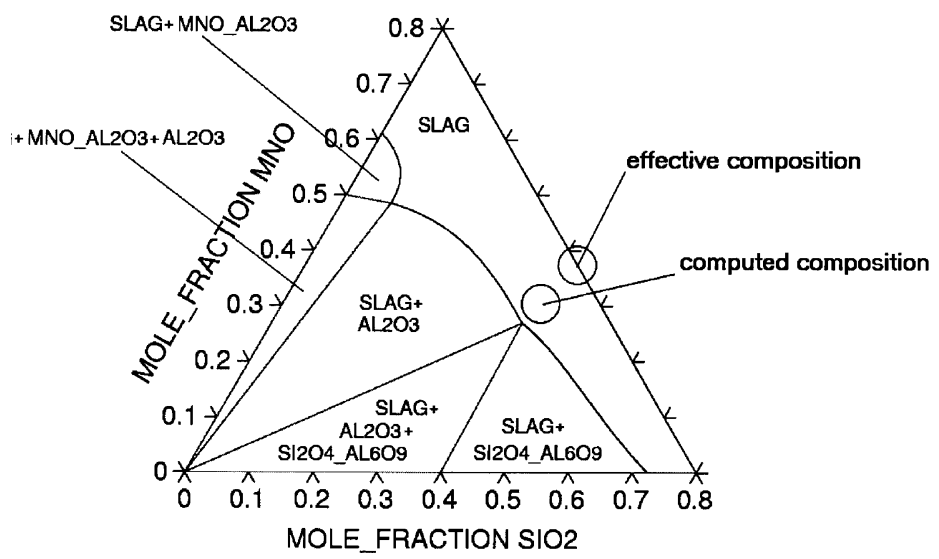

Fig. 9. Ternary diagram $\mathrm{SiO}_{2}-\mathrm{MnO}-\mathrm{Al}_{2} \mathrm{O}_{3}$ at $1933 \mathrm{~K}$. The effective and the computed compositions are shown for inclusions made mainly of these three oxides and observed after deoxidation with FeSi and SiMn.

perimental observations.

The effects of these corrections show how the model is influenced by the choice of the equilibrium constants and of other parameters such as the interaction coefficients and the coefficients of raoultian activity at infinite dilution.

The interaction coefficients has been revised for the whole system on the basis of more reliable data. ${ }^{8}$ However, it was observed that the quaternary system method is not reliable enough when in the system there are two or more elements that interact strongly; if this occurs, it will be necessary to consider systems larger than quaternary. Thus Janke's model, which was first applied with the quaternary system approach, was then extended, by increasing the number of the considered elements: this implied to increase the indexes in the formulas (3) and (4) from four to eight.

Thanks to Thermocalc ${ }^{\odot}$ it is possible to determine the composition the inclusions from the activities computed for the oxides by the extension of Janke's formalism. Especially interesting are those inclusions composed mainly of $\mathrm{SiO}_{2}, \mathrm{MnO}$ and $\mathrm{Al}_{2} \mathrm{O}_{3}$ found when the deoxidation is performed by adding $\mathrm{FeSi}$ and $\mathrm{SiMn}$. Below the reader can find the ternary diagram $\mathrm{SiO}_{2}-\mathrm{MnO}-\mathrm{Al}_{2} \mathrm{O}_{3}$ drawn by Thermocalc $^{\odot}$ at $1993 \mathrm{~K}$; there two areas are pointed out: one represents the effective, experimentally observed composition; the other represents the composition determined by computing the oxide activities at the equilibrium with the liquid steel. It can be noticed that the computed $\mathrm{Al}_{2} \mathrm{O}_{3}$ content is higher than that effectively measured, but the values are not significantly different.

\section{Conclusion}

The present study has been made to set the basis for further improvement in the knowledge of the evolution of the thermodynamic conditions during stainless steel refining. It was assessed how certain models, developed by other authors, could be applied to the study of this kind of alloys, in order to develop a mathematical tool to determine the types of inclusion that can form by calculating the activities of oxides at the equilibrium with the liquid steel. The model however considers only equilibriums and so it is not completely sufficient to explain the experimental observations.

For the calculation of the chemical elements activity in the liquid steel, a formalism by Janke et al. ${ }^{2)}$ has been used.
This formalism is more accurate than Wagner's one for the study of high-alloy steels like stainless steels. Janke's formalism was first used according to the quaternary systems method but later it was applied to systems having a number of elements higher than four, so that it was able to take into account all the interactions between elements. In this way the estimations of the activity values are more accurate than those given by the quaternary system approach, especially when there are two elements that interact strongly.

By comparing the oxide activities calculated at the equilibrium with the liquid metal to those obtained experimentally the following hypotheses were made:

- pure $\mathrm{Cr}_{2} \mathrm{O}_{3}$ forms during the oxidation and can act as nucleant for inclusions that precipitate during the reducing period, so being trapped and not reduced; for this oxide the calculated activities were much lower than those found experimentally;

- pure $\mathrm{SiO}_{2}$ inclusions can form at the beginning of the deoxidation and can be modified, if also SiMn is added in order to deoxidize the liquid steel, so that liquid inclusions containing $\mathrm{SiO}_{2}$ and $\mathrm{MnO}$ (together with other oxides however such as $\mathrm{Al}_{2} \mathrm{O}_{3}$ ); for this oxide the activity values obtained experimentally were higher than those computed, even if the differences were small;

- $\mathrm{Al}_{2} \mathrm{O}_{3}$ may have slow kinetics of nucleation; for alumina the activity values obtained experimentally were lower than those calculated.

It has been shown that the results of the model are influenced by the choice of some parameters such as the equilibrium constants and the interaction coefficients. Some combinations of these parameters lead to a better agreement between theoretical results and experimental results.

Another way to improve this agreement was the extension of Janke's model to systems larger than quaternary. This formalism proved suitable to study high-alloy steels like stainless steels and proved more accurate when it takes into account all the strong interactions between two system components. The activity of an element computed with this model can be significantly different, if another element that interacts strongly with the considered one is neglected. That's why the quaternary system approach fails: when it is used to calculate the activity of an element having high affinity to oxygen (e.g. Al), it neglects the interaction between them, thus giving a less accurate result. Even if the 
amount of oxygen in the steel is small, some of its interaction coefficients have a high value (especially the one between $\mathrm{O}$ and $\mathrm{Al}$ ), so that their interaction term has not to be neglected when calculating their activity.

Applying Janke's model to systems including almost all the elements present in the liquid steel, leads to a significant improvement of the model.

\section{REFERENCES}

1) M. Cusolito, C. Mapelli and W. Nicodemi: Metall. Sci. Technol., 20 (2002), 9.

2) D. Janke and Z. Ma: Steel Res., 10 (1999), 395.
3) H. Ohta and H. Suito: Metall. Mater. Trans. B, 29B (1998), 119

4) C. Bodsworth and H. B. Bell: Physical Chemistry of Iron and Steel Manufacture-2nd ed., Longman, London, (1972), 485.

5) R.G. Ward: Introduzione alla Chimica Fisica Siderurgica, Etas Kompass, Milan, (1969), 32

6) F. Oeters: Metallurgy of Steelmaking, Verlag Stahleisen $\mathrm{mbH}$, Düsseldorf, (1994), 15

7) I. Barin, O. Knacke and O. Kubaschewski: Thermochemical Properties of Inorganic Substances, Springer-Verlag, Berlin, (1973), 1.

8) P. Valentin, A. Heinen, S.Landa, D. Janke and Z. Ma: Improvement of cleanness and grain size in Ca-treated and $\mathrm{Al}$ deoxidised steels with high S-contents in billet and bloom casting, European Commision, Final report, European Commission, Brussels (1999), 73. 